\title{
Relativistically Parameterized Extended Hückel Calculations. 10. Lanthanide Trihalides
}

\author{
LAWRENCE L. LOHR* and Y. Q. JIA** \\ Department of Chemistry, University of Michigan, Ann Arbor, Mich. 48109, U.S.A.
}

(Received February 25, 1986; revised May 26, 1986)

\begin{abstract}
The REX relativistically parameterized extended Hückel method is used to study the electronic structure of lanthanide trihalide molecules. All valence orbitals are described in terms of double-zeta Slater functions, with the atomic orbital parameters being determined by a least-squares fitting to published relativistic (Dirac Fock) radial densities. Comparisons of orbital energies to experimental values are made and various trends are discussed. $A b$ initio all-electron calculations at the self-consistent field level and as a function of molecular geometry are reported for $\mathrm{LaH}_{3}, \mathrm{LaF}_{3}$, and $\mathrm{LaCl}_{3}$. While $\mathrm{LaH}_{3}$ and $\mathrm{LaF}_{3}$ are calculated to be pyramidal, $\mathrm{LaCl}_{3}$ is calculated to be planar.
\end{abstract}

\section{Introduction}

The gaseous lanthanide trihalides have been the subject of numerous experimental and theoretical investigations. The experimental investigations have included electric-field deflection [1], electron diffraction [2], and photoelectron spectroscopy (PES) [3-5], with related PES studies [6-8] having been carried out for the solid trifluorides. The theoretical investigations have included calculations at the extended Hückel (EH) [9-10], INDO [11], multiple-scattering $\mathrm{X} \alpha(\mathrm{MS}-\mathrm{X} \alpha)[12,13]$ and relativistic discrete variational $\mathrm{X} \alpha(\mathrm{DVM})$ [5] levels. We earlier published [14] relativistic extended Hückel results (REX) for $\mathrm{LaI}_{3}, \mathrm{GdI}_{3}$ and $\mathrm{LuI}_{3}$ with the focus being upon the equilibrium geometry of these molecules. The best of the theoretical studies is the relativistic DVM study [5] based on assumed structures (mostly planar). In order to explore further not only the structural question but also the spin-orbit splittings of the occupied valence and core levels, we present here some further REX results augmented

\footnotetext{
*Author to whom correspondence should be addressed.

**Permanent address: Changchun Institute of Applied Chemistry, Academia Sinica, Changchun, Jilin, China.
}

by selected non-relativistic all-electron $a b$ initio results. The REX method [15-16] has been used in describing [18-25] various properties, including nuclear spin-spin couplings, of heavy-element compounds.

\section{Double-zeta Atomic Functions}

Slater-type radial wave functions are widely used in semi-empirical quantum chemical calculations, with double-zeta functions generally providing more satisfactory results than single-zeta functions. Earlier papers in this series $[17,22-23]$ have reported double-zeta parameters for halogens and actinides. These parameters were typically obtained by a fitting of the radial density to that calculated by Desclaux [26] using numerical Hartree-Fock (HF) or Direc-Fock (DF) procedures. Single-zeta exponents for the lanthanides have been obtained from atomic self-consistent field (SCF) calculations by Clementi et al. [27] and from fits to HF or DF radial expectation values by $\mathrm{Li}$ et al. [11] and by us [15, 16]. Double-zeta parameters for transition metals have recently been reported by Fitzpatrick and Murphy [28].

In our present study we have obtained doublezeta parameters for the $6 \mathrm{~s}, 5 \mathrm{p}_{1 / 2}, 5 \mathrm{p}_{3 / 2}, 5 \mathrm{~d}_{3 / 2}, 5 \mathrm{~d}_{5 / 2}$, $4 f_{5 / 2}$, and $4 f_{7 / 2}$ shells of the elements La through Lu. Again these have been based on Desclaux' numerical DF atomic wave functions, but rather than a fitting to the radial density, a least-squares fitting to DF radial expectation values was employ. ed. We have also obtained by this procedure a new set of double-zeta parameters for the $n \mathrm{~s}, n \mathrm{p}_{1 / 2}$, and $n \mathrm{p}_{3 / 2}$ shells of the halogens $\mathrm{F}(n=2)$ through I $(n=5)$. Our earlier experience was that such a procedure occasionally produced unstable fittings, but our present procedure is more satisfactory. A double-zeta function of given principal quantum number contains two exponents and two linear coefficients. In the first stage of our fittings, we take these as four independent parameters to be adjusted by a least-squares procedure to fit the set of four DF radial expectation values $\left\langle r^{k}\right\rangle, k=2,1,0$ and -1 . Thus the norma- 
TABLE I. Double-zeta Parameters and Energy Parameters for Selected Lanthanides ${ }^{\text {a,b,c }}$

\begin{tabular}{|c|c|c|c|c|c|c|}
\hline Atom & $\begin{array}{l}\text { Atomic } \\
\text { orbital }\end{array}$ & $C_{1}$ & $\zeta_{1}$ & $C_{2}$ & $\xi_{2}$ & $-E(\mathrm{eV})$ \\
\hline \multirow[t]{6}{*}{$\mathrm{La}$} & $6 s$ & 0.554609 & 1.953578 & 0.589752 & 1.042466 & 4.89 \\
\hline & $5 p$ & 0.476821 & 5.014282 & 0.682859 & 2.370811 & 27.78 \\
\hline & $5 p^{*}$ & 0.522058 & 4.933225 & 0.631565 & 2.402945 & 30.51 \\
\hline & $5 \mathrm{~d}$ & 0.572423 & 2.922350 & 0.600120 & 1.357840 & 6.35 \\
\hline & $5 d^{*}$ & 0.596218 & 2.901245 & 0.575124 & 1.352633 & 6.48 \\
\hline & $(4 f)$ & 0.473645 & 8.700132 & 0.733310 & 3.215338 & 9.42 \\
\hline \multirow[t]{6}{*}{$\mathrm{Nd}$} & $6 \mathrm{~s}$ & 0.535387 & 1.969653 & 0.609236 & 1.043426 & 4.74 \\
\hline & $5 p$ & 0.476821 & 5.014282 & 0.682859 & 2.370811 & 26.89 \\
\hline & $5 p^{*}$ & 0.562016 & 4.867585 & 0.583374 & 2.436657 & 30.14 \\
\hline & $(5 d)$ & 0.767605 & 2.776867 & 0.377059 & 1.303870 & $(6.30,6.46)$ \\
\hline & $4 \mathrm{f}$ & 0.458016 & 8.643562 & 0.745092 & 3.202980 & 12.67 \\
\hline & $4 f^{*}$ & 0.469666 & 8.599291 & 0.733399 & 3.214391 & 13.04 \\
\hline \multirow[t]{7}{*}{ Gd } & $6 s$ & 0.694744 & 1.973528 & 0.448731 & 1.027802 & 5.44 \\
\hline & $5 p$ & 0.611170 & 4.795486 & 0.520638 & 2.486839 & 32.70 \\
\hline & $5 p^{*}$ & 0.673131 & 4.711819 & 0.436953 & 2.562657 & 37.34 \\
\hline & $5 \mathrm{~d}$ & 0.721038 & 2.806742 & 0.461175 & 1.229689 & 5.97 \\
\hline & $5 \mathrm{~d}^{*}$ & 0.827562 & 2.734545 & 0.360506 & 1.069351 & 6.14 \\
\hline & $4 f$ & 0.636189 & 8.031788 & 0.533169 & 3.451086 & 14.95 \\
\hline & $4 f^{*}$ & 0.645464 & 8.003089 & 0.520126 & 3.470138 & 15.71 \\
\hline \multirow[t]{7}{*}{$\mathrm{Lu}$} & $6 s$ & 0.817347 & 2.008402 & 0.323628 & 0.968808 & 6.00 \\
\hline & $5 p$ & 0.719122 & 4.656918 & 0.371444 & 2.639202 & 36.95 \\
\hline & $5 p^{*}$ & 0.848037 & 4.518940 & 0.192191 & 2.848987 & 44.24 \\
\hline & $5 \mathrm{~d}$ & 0.750661 & 2.786901 & 0.450971 & 1.141330 & 5.04 \\
\hline & $5 \mathrm{~d}^{*}$ & 0.800069 & 2.755971 & 0.396519 & 1.090771 & 5.21 \\
\hline & $4 f$ & 0.779192 & 7.632421 & 0.313140 & 3.883810 & 16.02 \\
\hline & $4 f^{*}$ & 0.787354 & 7.581198 & 0.283276 & 3.871316 & 17.77 \\
\hline
\end{tabular}

${ }^{\mathrm{a}}$ For $l \neq 0, n l$ denotes $j=l+1 / 2$, while $n l^{*}$ denotes $j=l-1 / 2, \quad \mathbf{b}_{\text {The notation }(n l) \text { denotes use of the same parameters for } j=l+}$ $1 / 2$ and $j=l-1 / 2$; where two values of $-E$ are given, the first is for $n l$, the second for $n l^{*}$. ${ }^{\mathbf{c}}$ For all 15 elements La through Lu, see 'Supplementary Material'.

lization condition $\left\langle r^{0}\right\rangle=1$ is implicitly rather than explicitly incorporated. The use of four parameters with four conditions inplies that an exact fitting is possible. However, the final stages of convergence are slow, so that after a reasonably satisfactory fit has been found, typically after 5 to 10 cycles, the least-squares process is stopped and the linear coefficients are adjusted to give an exactly normalized function. These final adjustments are small, as the sum of the squares of the differences between the input and calculated values of the $\left\langle r^{k}\right\rangle$ is typically 0.01 at this point, with distances in atomic units (a.u.) or Bohr.

In Fig. 1 we compare the radial density calculated from our double-zeta function for the $7 \mathrm{~s}$ orbital of $U$ to that calculated from Pyykkö and Laaksonen's (P-L) double-zeta function [23] and to that calculated from a single-zeta function fitted to the mean value of $r(\zeta(7 \mathrm{~s})=1.728)$. We note that our double-zeta function is somewhat more contracted than the P-L function as compared to the single-

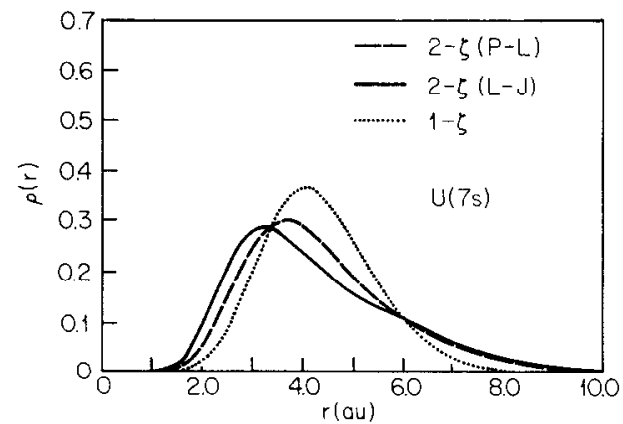

Fig. 1. Comparison of radial densities $\rho(r)=r^{2} R^{2}(r)$ for $\mathrm{U}(7 \mathrm{~s})$ as obtained from our double-zeta function ( - ), the Pyykkö-Laaksonen (ref. 23) double-zeta function (- - ), and a single-zeta function $(\cdots$,$) with \zeta=1.728$. Distance is in atomic units (a.u.) (Bohr).

zeta function, but the difference does not appear significant for our semi-quantitative purposes.

We list in Tables I and II the double-zeta coefficients and exponents thereby obtained for the lantha- 
TABLE II. Double zeta Parameters and Energy Parameters ${ }^{\mathrm{a}}$ for Halogens

\begin{tabular}{llllllr}
\hline Atom & $\begin{array}{l}\text { Atomic } \\
\text { orbital }\end{array}$ & $C_{1}$ & $\xi_{1}$ & $C_{2}$ & $\zeta_{2}$ & $-E(\mathrm{eV})$ \\
\hline $\mathrm{F}$ & $2 \mathrm{~s}$ & 0.642565 & 2.616176 & 0.357451 & 2.589120 & 34.89 \\
& $2 \mathrm{p}$ & 0.525985 & 2.632205 & 0.487474 & 1.959236 & 13.83 \\
$\mathrm{Cl}$ & $2 \mathrm{p}^{*}$ & 0523319 & 2.642499 & 0.490315 & 1.963235 & 13.90 \\
& $3 \mathrm{~s}$ & 0.772504 & 2.524923 & 0.252063 & 1.698524 & 23.38 \\
$\mathrm{Br}$ & $3 \mathrm{p}$ & 0.688138 & 2.222300 & 0.354653 & 1.379071 & 11.72 \\
& $3 \mathrm{p}^{*}$ & 0683790 & 2.233997 & 0.358314 & 1.393848 & 11.86 \\
$\mathrm{I}$ & $4 \mathrm{~s}$ & 0.685466 & 3.156290 & 0.373837 & 1.925222 & 23.78 \\
& $4 \mathrm{p}$ & 0.576701 & 3.089149 & 0.547709 & 1.532434 & 1123 \\
& $4 \mathrm{p}^{*}$ & 0.635842 & 3.025343 & 0.487968 & 1.491662 & 11.79 \\
& $5 \mathrm{~s}$ & 0.542381 & 4.313218 & 0.619170 & 2.060634 & 20.86 \\
& $5 \mathrm{p}$ & 0.435694 & 3.774910 & 0.723409 & 1.755239 & 9.58 \\
& $5 \mathrm{p} *$ & 0.484959 & 3.704515 & 0.669183 & 1.785650 & 10.72 \\
\hline
\end{tabular}

${ }^{\mathrm{a}}$ For $l=1, n$ p denotes $j=3 / 2$, while $n \mathrm{p}^{*}$ denotes $j=1 / 2$.

nides $\mathrm{La}, \mathrm{Nd}, \mathrm{Gd}$, and $\mathrm{Lu}$ and for the halides. Also listed are the orbital energy parameters as used in our REX calculations. See also 'Supplementary Material'. The energy parameters are basically Desclaux' DF orbital energies [26], but have been shifted by the following amounts in $\mathrm{eV}$ : $\mathrm{Ce}(4 \mathrm{f}),+4 ; \operatorname{Pr}(4 \mathrm{f})$ through $\mathrm{Eu}(4 \mathrm{f}),-3 ; \mathrm{Gd}(4 \mathrm{f}),+4.4 ; \mathrm{Tb}(4 \mathrm{f})$ through $\mathrm{Yb}(4 \mathrm{f})$, $-3 ; \mathrm{Lu}(4 \mathrm{f}),+5.5 ; \mathrm{F}(2 \mathrm{~s}),+8 ; \mathrm{F}(2 \mathrm{p})$ and $\mathrm{Cl}(3 \mathrm{~s})$, +6; $\mathrm{Cl}(3 \mathrm{p}),+2 ; \mathrm{Br}(4 \mathrm{~s}),+4 ; \mathrm{Br}(4 \mathrm{p}),+1 ; \mathrm{I}(5 \mathrm{~s}),+3 ;$ and $\mathrm{I}(5 \mathrm{p}),+1$. In each case both $j$-levels for a given $n$ and $l$ were given the same shift. The basic direction of these shifts were chosen to raise the halogen levels and lower the $\mathrm{Ln}(4 \mathrm{f})$ levels; the $\mathrm{Ce}, \mathrm{Gd}$, and $\mathrm{Lu} \mathrm{DF}$ atomic eigenvalues were already very low (negative) and were raised, giving $4 \mathrm{f}$ values varying smoothly (Fig. 2) with atomic number $Z$. The La(4f) value

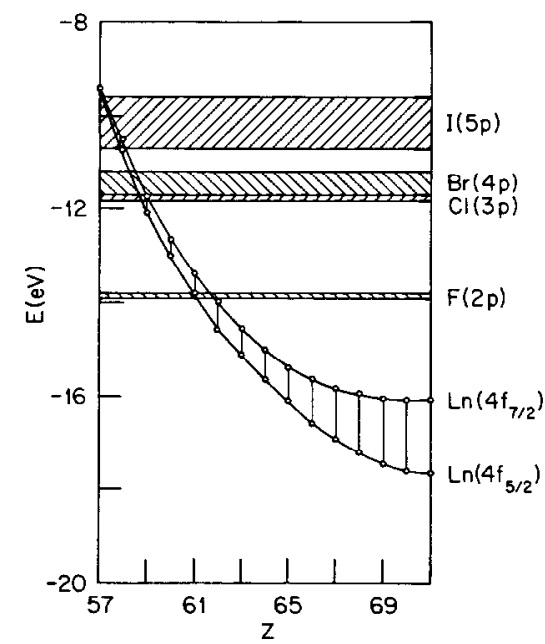

Fig. 2. Orbital energies in $\mathrm{eV}$ for $\operatorname{Ln}(4 f)$ and $\mathrm{X}(n \mathrm{p})$ levels. The width of the shaded band for each $X(n p)$ level denotes the separation between $\mathrm{X}\left(n \mathrm{p}_{3 / 2}\right)$ and $\mathrm{X}\left(n \mathrm{p}_{1 / 2}\right)$. The energies are the neutral atom Dirac-Fock values of Desclaux (ref. 26), but shifted as described in the text. was obtained as $-9.42 \mathrm{eV}$ by extrapolation and used for both $4 f_{5 / 2}$ and $4 f_{7 / 2}$. A key feature of these parameters is that the $\operatorname{Ln}(4 \mathrm{f})$ levels lie at least $1 \mathrm{eV}$ below the $\mathrm{X}(n \mathrm{p})$ levels for $\mathrm{Pr}$ to $\mathrm{Lu}$ for $\mathrm{X}=\mathrm{I}, \mathrm{Nd}$ to $\mathrm{Lu}$ for $\mathrm{X}=\mathrm{Br}$ or $\mathrm{Cl}$, and $\mathrm{Eu}$ to $\mathrm{Lu}$ for $\mathrm{X}=\mathrm{F}$, so that in these cases the $4 \mathrm{f}$ levels may be considered to be core-like. Only for $\mathrm{LaF}_{3}$ to $\mathrm{NdF}_{3}, \mathrm{LaCl}_{3}, \mathrm{LaBr}_{3}$, $\mathrm{CeCl}_{3}$, and $\mathrm{CeBr}_{3}$ are the $4 \mathrm{f}$ levels appreciably above the $\mathrm{X}(n \mathrm{p})$ levels.

\section{REX Orbital Energies for $\operatorname{LnX} 3$}

We have carried out REX calculations for all 60 of the molecules $\mathrm{LnX}_{3}$, with $\mathrm{Ln}=\mathrm{La}$ to $\mathrm{Lu}$ and $\mathrm{X}=$ $\mathrm{F}$ to $\mathrm{Cl}$, assuming for the halides of $\mathrm{La}, \mathrm{Ce}, \mathrm{Nd}, \mathrm{Gd}$, $\mathrm{Er}$, and Lu the same geometries (Table III) as used by Rušcić et al. [5] in their relativistic $\mathrm{X} \alpha$ studies. These geometries are planar $\left(D_{3 h}\right)$, except for $\mathrm{LaCl}_{3}$, $\mathrm{CeCl}_{3}, \mathrm{LuCl}_{3}, \mathrm{CeBr}_{3}, \mathrm{NdBr}_{3}, \mathrm{GdBr}_{3}$, and $\mathrm{LuBr}_{3}$, which are pyramidal $\left(C_{3 v}\right)$. The fluorides and iodides of the remaining lanthanides were assumed to be planar, while the chlorides and bromides were assumed to be pyramidal. We seriously doubt the correctness of many of these structural assignments, but

TABLE III LnX $_{3}$ Geometries ${ }^{\mathbf{a}}$ used in REX Calculations

\begin{tabular}{lcccc}
\hline & La & Nd & Gd & Lu \\
\hline $\mathrm{F}$ & 2.22 & 2.15 & 2.10 & 2.02 \\
& 120 & 120 & 120 & 120 \\
$\mathrm{Cl}$ & 2.587 & 2.545 & 2.489 & 2.417 \\
& 112.5 & 120 & 120 & 111.5 \\
$\mathrm{Br}$ & 2.741 & 2.689 & 2.640 & 2.56 \\
& 120 & 111 & 113.8 & 114 \\
$\mathrm{I}$ & 2.946 & 2.894 & 2.845 & 2.766 \\
& 120 & 120 & 120 & 120 \\
\hline
\end{tabular}

${ }^{a}$ Bond lengths in $\AA$ and bond angles in degrees from ref. 5. 


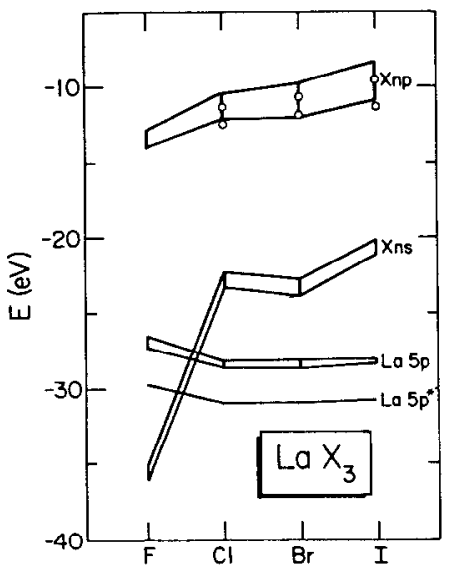

Fig. 3. REX orbital energies in $\mathrm{eV}$ for $\mathrm{LaX}_{3}$ using parameters from Tables I and II and geometrics from Table III (ref. 5). The levels are labeled by the atomic orbital (AO) which is the principal component of each MO. Only the highest and lowest energy are shown for each group of levels. Circled points are experimental PES values (refs. 3-5). The notation $n l^{*}$ and $n l$ for Ln denote $j=1-1 / 2$ and $j=l+1 / 2$, respectively.

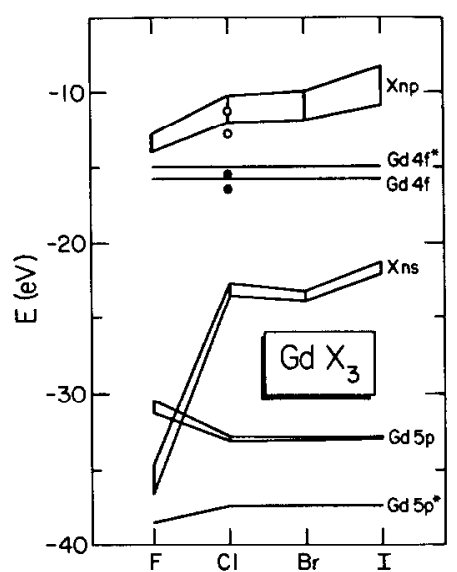

Fig. 4. As in Fig. 3, but for $\mathrm{NdX}_{3}$. The open (O) and closed (•) circled points denote experimental PES values (refs. 3-5) assigned to $\mathrm{X}(n \mathrm{p})$ and $\operatorname{Ln}(4 \mathrm{f})$ levels, respectively.

they do facilitate comparisons between the REX and $\mathrm{X} \alpha$ results. In Figs. 3-6 we present the results for the halides of $\mathrm{La}, \mathrm{Nd}, \mathrm{Gd}$, and $\mathrm{Lu}$; experimental PES [3-5] data are also shown as available.

We show the REX orbital energies for the X $(n p)$, $\mathrm{X}(n \mathrm{~s}), \operatorname{Ln}(5 \mathrm{p})$, and $\operatorname{Ln}(4 \mathrm{f})$ (if occupied) levels. For $\mathrm{X}(n \mathrm{p})$ and $\mathrm{X}(n \mathrm{~s})$ we show only the highest and lowest energy levels of each group of levels, thus defining a 'band width'. For $\operatorname{Ln}(5 \mathrm{p})$ we show the $\mathrm{p}_{1 / 2}$ (denoted $\mathrm{p}^{*}$ ) and the crystal-field split $\mathrm{p}_{3 / 2}$ (denoted p) levels. For $\operatorname{Ln}(4 f)$ we show the $f_{s / 2}$ (denoted $f^{*}$ ) and $\mathrm{f}_{7 / 2}$ levels (denoted f), but typically do not show the very small crystal-field splittings of each of these $j$ levels. Several features are common to all of the $\mathrm{LnX}_{3}$ results. The X(np) levels rise in energy (a reflection of the input atomic energies) and increase in

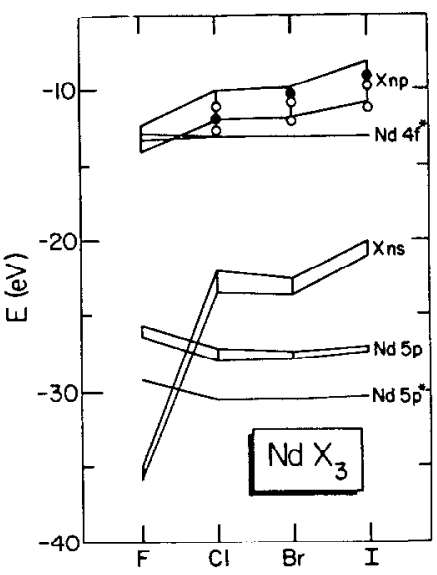

Fig. 5. As in Fig. 4, but for $\mathrm{GdX}_{3}$.

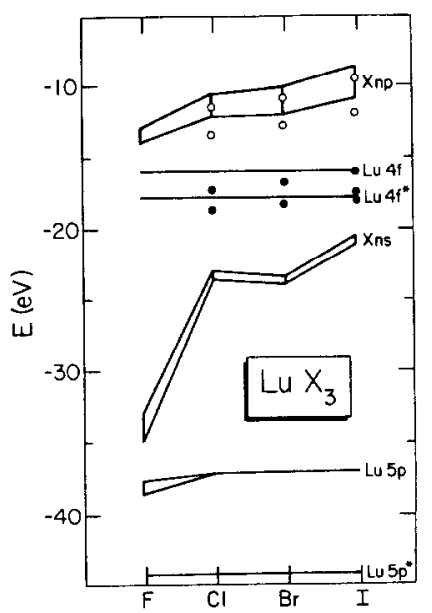

Fig. 6. As in Fig. 4, but for $\mathrm{LuX}_{3}$.

band width (a consequence of spin-orbit splitting and intramolecular interaction) for $F$ to I. Specifically, the width increases from approximately 1.2 $\mathrm{eV}$ to $2.8 \mathrm{eV}$, matching well the observed increases for $\mathrm{La}, \mathrm{Gd}$, and $\mathrm{Lu}$. At the single-zeta level the widths are smaller than at the double-zeta level, an example being 1.65 vs. $2.34 \mathrm{eV}$ for $\mathrm{LuI}_{3}$. The $\mathrm{X}(n \mathrm{~s})$ levels are narrow in width, typically 0.25 to $1.0 \mathrm{eV}$. An exception is $\mathrm{GdF}_{3}$, as in our parameterization the $F(2 \mathrm{~s})$ atomic level at $-34.89 \mathrm{eV}$ is nearly degenerate with the $\operatorname{Gd}\left(5 p_{1 / 2}\right)$ and $\left(5 p_{3 / 2}\right)$ levels at -37.34 and $-32.70 \mathrm{eV}$, respectively. As a consequence the predominantly $F(2 s)$ band shows (Fig. 5) a width of approximately $2.0 \mathrm{eV}$. The $\operatorname{Ln}\left(5 \mathrm{p}_{3 / 2}\right)$ level shows a crystal-field splitting that is small $(0.25$ to $0.75 \mathrm{eV})$ compared to the $\mathrm{p}_{3 / 2}-\mathrm{p}_{1 / 2}$ spin-orbit splitting of $2.73(\mathrm{La})$ to $7.29 \mathrm{eV}(\mathrm{Lu})$ and that typically decreases in going from $\mathrm{F}$ to $\mathrm{I}$ and in going from $\mathrm{La}$ to $\mathrm{Lu}$. The $\operatorname{Ln}\left(5 \mathrm{p}_{1 / 2}\right)$ and $\left(\mathrm{p}_{3 / 2}\right)$ levels become increasingly core-like as $Z$ increases, with energy lowerings in our input parameters of 13.73 and 9.13 $\mathrm{eV}$, respectively, in going from $\mathrm{La}$ to $\mathrm{Lu}$. 
The $\operatorname{Ln}\left(4 f_{7 / 2}\right)$ and $\left(f_{5 / 2}\right)$ levels have from our parameterization a spin orbit separation that agrees well with that observed for $\mathrm{GdX}_{3}$ and $\mathrm{LuX}_{3}$ (Figs. 5 and 6) The absolute position of these levels is largely determined by the assumed shifts of the atomic DF values as described at the end of 'Section II'. An interesting experimental result that we cannot reproduce with the present non-iterative (no charge selfconsistency) version of REX is the rise in the $4 f$ levels of approximately 0.5 to $0.75 \mathrm{eV}$ in going from $\mathrm{Cl}$ to $\mathrm{Br}$ or $\mathrm{Br}$ to $\mathrm{I}$. As the $4 \mathrm{f}$ levels are core-like in their radial distribution even when their energy is high; this rise is best interpreted as a binding energy chemical shift Thus it reflects the change in the electrostatic potential at or near the $\mathrm{Ln}$ nucleus accompanying a change of $X$, and in no way indicates $4 \mathrm{f}$ covalency. We can easily change the input $4 \mathrm{f}$ energies to fit the observed ionization energies for any given $\operatorname{Ln} X_{3}$, but any particular choice does not fit for all X. We do note that our computed Mulliken charges on $L n$ decrease in going from $F$ to $I$, an example being $\mathrm{LuX}_{3}$ for which the charges are 2.82, 2.37, 2.31, and 2.01 for $\mathrm{X}=\mathrm{F}, \mathrm{Cl} \mathrm{Br}$, and $\mathrm{I}$, respectively These changes are in the direction which would produce rises in the $4 \mathrm{f}$ energies (decreases in the ionization energies) and reflect increased occupancy of the $6 \mathrm{~s}$ and $5 \mathrm{~d}$ levels of Lu. Specifically the Mulliken orbital charges for $\mathrm{LuX}_{3}, \mathrm{X}=\mathrm{F}, \mathrm{Cl}, \mathrm{Br}$, and $I$, are $0.029,0.156,0.168$, and 0.245 for $6 \mathrm{~s}$, $0.070,0.196,0.220$, and 0.326 for $5 d_{3 / 2}$, and 0.090 , $0.284,0.307$, and 0.424 for $5 \mathrm{~d}_{5 / 2}$

\section{Ab Initio Calculations for $\mathrm{LaH}_{3}, \mathrm{LaF}_{3}$, and $\mathrm{LaCl}_{3}$}

In order to explore further the question of the equilibrium geometry of $\operatorname{Ln} X_{3}$ molecules we carried out geometry optimizations for $\mathrm{LaH}_{3}, \mathrm{LaF}_{3}$ : and $\mathrm{LaCl}_{3}$ using analytical energy gradients and the $a b$ initio GAUSSIAN 82 program [29]. The calculations were made at the single-determinantal (self-consistent field or SCF) level and employed for $\mathrm{La}$ a minimal (3G) basis set published by Huzinaga [30] for the shells $1 \mathrm{~s}$ to $6 \mathrm{~s} 2 \mathrm{p}$ to $5 \mathrm{p}$ and $3 \mathrm{~d}$ to $4 \mathrm{~d}$. We augmented this set with single Gaussian basis functions for the $5 \mathrm{~d}$ and $6 \mathrm{p}$ shells, with exponents of 0.2725 and 0.05 , respectively. As the $5 \mathrm{~d}$ function is expected to be particularly important in describing La compounds its exponent was chosen by mini mization of the energy of $\mathrm{LaF}_{3}\left(D_{3 h}\right)$ with $\mathrm{La}-\mathrm{F}=$ $2.20 \AA$ The exponent for the less important $6 \mathrm{p}$ function was simply selected to be approximately onehalf of the smallest p-exponent in the minimal basis set For each of the three d-shells only the set of five true $\mathrm{d}$ functions were employed. For $\mathrm{H}$ we employed the split-valence $31 \mathrm{G}$ basis commonly used with $6.31 \mathrm{G}$ basis sets [31] for main-group elements, while for $\mathrm{F}$ and $\mathrm{Cl}$ we employed the minimal 3G basis sets
TABLE IV. Ab Initio Equilibrium Geometries and Relative Energies

\begin{tabular}{llllr}
\hline Molecule & Symmetry & $\mathrm{MX}^{\mathrm{a}}$ & $\mathrm{XMX}^{\mathrm{b}}$ & $\Delta E^{\mathrm{c}}$ \\
\hline $\mathrm{LaH}_{3}$ & $C_{3 v}$ & 2.129 & 114.7 & 0 \\
& $D_{3 h} \mathrm{~d}$ & 2.137 & 120.0 & 239 \\
$\mathrm{LaF}_{3}$ & $C_{3 v}$ & 2.080 & 112.0 & 0 \\
& $D_{3 h} \mathrm{~d}$ & 2.089 & 120.0 & 921 \\
$\mathrm{LaCl}_{3}$ & $D_{3 h}$ & 2.623 & 120.0 & 0 \\
& $C_{3 v} \mathrm{e}$ & 2.613 & 112.0 & $381^{\mathrm{f}}$ \\
\hline
\end{tabular}

${ }^{a}$ Bond length $M-X$ in $\AA . \quad b_{B o n d}$ angle $X-M-X$ in deg. ${ }^{\mathrm{c}} E\left(D_{3 h}\right)-E\left(C_{3 v}\right)$ in $\mathrm{cm}^{-1}$ except for $\mathrm{LaCl}_{3}$. ${ }^{\mathrm{d}}$ Unstable with respect to out-of-plane deformation. ${ }^{\mathbf{e}}$ Non-equilibrium structure with bond angle assumed to be the same as that computed for $\mathrm{LaF}_{3} . \quad{ }^{\mathrm{f}} E\left(C_{3 v}\right)-E\left(D_{3 h}\right)$.

of Huzinaga. Optimizations were carried out with $D_{3 h}$ and with $C_{3 v}$ symmetry constraints.

We find (Table IV) the pyramidal $C_{3 v}$ structure found to be favored for $\mathrm{IaH}_{3}$ and $\mathrm{IaF}_{3}$, although by only $239 \mathrm{~cm}^{-1}$ for $\mathrm{LaH}_{3}$. By contrast we find the planar $D_{3 h}$ form of $\mathrm{LaCl}_{3}$ to be stable with respect to the out-of-plane deformation. The computed $\mathrm{La}-\mathrm{H}$ bond length is approximately $0.05 \AA$ longer than the $\mathrm{La}-\mathrm{F}$ length, a result consistent with a mostly ionic description of the bonding. Interestingly our computed distances of 2.129 and $2.080 \AA$ for $\mathrm{LaH}_{3}$ and $\mathrm{LaF}_{3}$, respectively, are similar to the observed [32] distances of 2.110 and 2.097 $\AA$ for the ${ }^{1} \pi$ states of the corresponding diatomics $\mathrm{LaH}$ and $\mathrm{LaF}$. The gaseous Cs diatomics show an even greater difference between bond lengths to $\mathrm{H}$ and to F, namely observed [32] distances of 2.4938 and $2.3454 \AA$ for $\mathrm{CsH}$ and $\mathrm{CsF}$, respectively. The Mulliken charges on $\mathrm{La}$ are similar for all three molecules, namely +1.62 and +1.66 for the $C_{3 v}$ forms of $\mathrm{LaH}_{3}$ and $\mathrm{LaF}_{3}$, respctively, and +1.75 for the $D_{3 h}$ form of $\mathrm{LaCl}_{3}$. We also note that the calculated $\mathrm{La}-\mathrm{F}$ and $\mathrm{La}-\mathrm{Cl}$ bond lengths are considerably shorter than the distances observed $[33,34]$ in the crystalline trihalides; 2.08 vs. $2.36 \AA$ for $\mathrm{LaF}_{3}$ and 2.62 vs. $2.95 \AA$ for $\mathrm{LaCl}_{3}$. Although our computed distances may be too short, we do believe the trend to be correct. For example, observed distances for $\mathrm{CsF}$ are 2.3454 and $3.005 \AA$ in the molecule [32] and in the solid [33], respectively, with the corresponding distances for other alkali halides also showing a significant contraction in going from the solid to the molecule. As our $a b$ initio results are based on the use of small basis sets and do not incorporate either correlation or zero-point energy corrections, we attach to them only semi-quantitative significance. They do offer some support to the expectation of a non-planar equilibrium geomtry for at least some of the $\mathrm{LnX}_{3}$ molecules. 


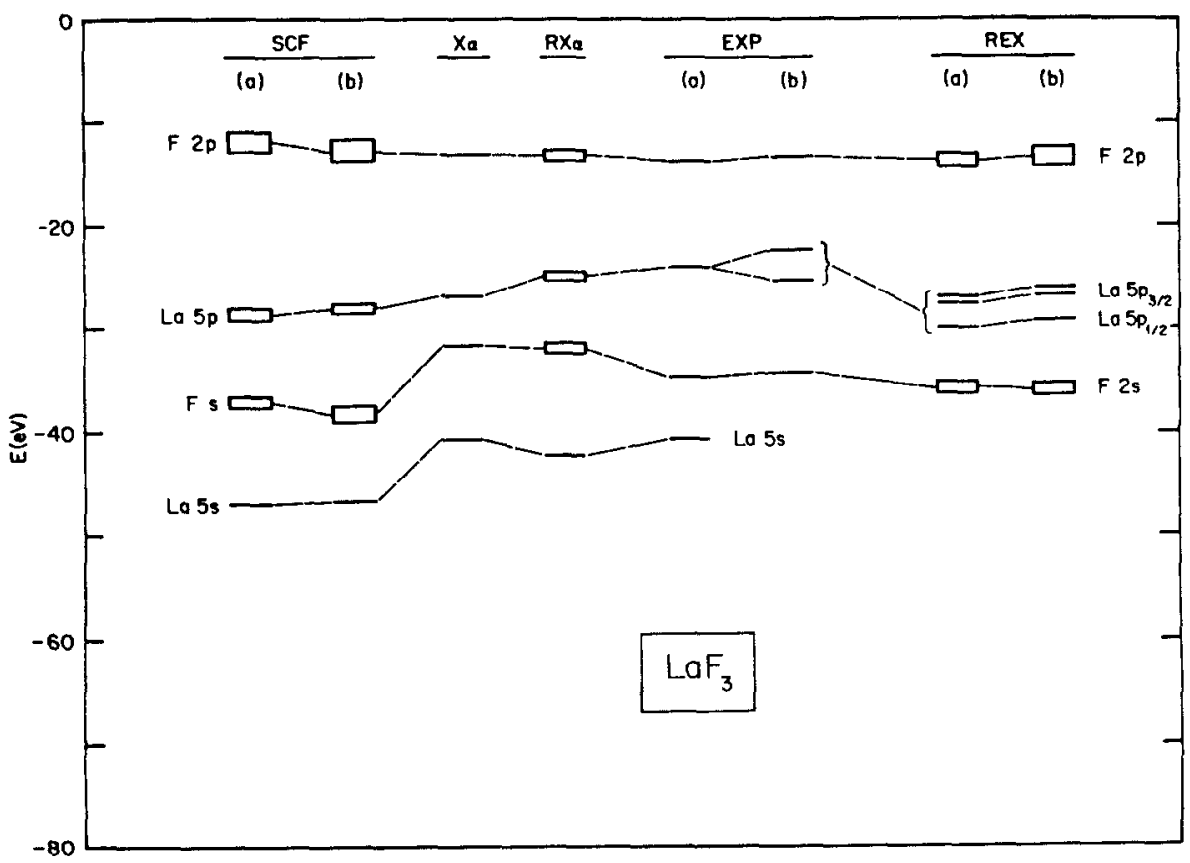

Fig. 7. Orbital energies for $\mathrm{LaF}_{3}$ at various levels. SCF denotes $a b$ initio values obtained using an augmented STO-3G basis for optimized structures obtained for assumed (a) $D_{3 h}$ and (b) $C_{3 v}$ structures. REX denotes relativistically parameterized extended Hückel values at the SCF (a) $D_{3 h}$ and (b) $C_{3 v}$ geometries. X $\alpha$ and $\mathrm{RX} \alpha$ denote the non-relativisitic and relativistic X $\alpha$ calculations or Weber et al. (ref. 12) and of Rứcić et al. (ref. 5), respectively. The experimental (EXP) values are from (a) Weber et al. and (b) Wertheim et al. (ref. 6), both sets being for the solid state. With the exception of the REX La(5p) levels only band widths rather than individual levels are shown.

The experimental situation with respect to the structural question is not conclusive. From electricfield deflection studies [1], Kaiser et al. concluded that the fluorides of $\mathrm{La}, \mathrm{Gd}$, and $\mathrm{Lu}$ were polar and therefore pyramidal, those of $\mathrm{Tm}, \mathrm{Ce}$, and $\mathrm{Er}$ were probably polar, and those of $\mathrm{Nd}, \mathrm{Pr}, \mathrm{Tb}, \mathrm{Dy}$, and $\mathrm{Ho}$ were non-polar and therefore planar; no conclusions could be drawn about the fluorides of $\mathrm{Sm}, \mathrm{Eu}$, and $\mathrm{Yb}$. Electron diffraction data have suggested [2] pyramidal structures for the iodides of $\mathrm{Pr}, \mathrm{Nd}, \mathrm{Gd}$, and $\mathrm{Lu}$.

In Fig. 7 we summarize our findings for the orbital energies of $\mathrm{LaF}_{3}$. Shown are the SCF $a b$ initio and REX values, with both being for the (a) $D_{3 h}$ and (b) $C_{3 v}$ SCF geometries given in Table IV. We note that both the SCF and REX values are rather insensitive to the geometry change as compared to the relatively large energy separations between the energy 'bands'. Also shown are the non-relativistic and relativistic $\mathrm{X} \alpha$ values of Weber et al. [12] and Ruscić et al. [5], respectively. The experimental values shown are from the solid-state data of Weber et al. [12] and Wertheim et al. [6]. Overall there is general agreement among the various computational levels and between computation and experiment. The SCF $\mathrm{La}(5 \mathrm{~s})$ and (5p) energies are too low, probably reflecting an excessively ionic description arising in part from the SCF approximation and in part from basis set inadequacies. The fine-structure obtained at the REX level for the $\operatorname{La}(5 p)$ levels is shown in detail; the overall band width matches the observed width better than does the relativistic $\mathrm{X} \alpha$ width, although the absolute REX energies are approximately $4 \mathrm{eV}$ too low.

\section{Conclusion}

We have obtained a set of double-zeta Slatertype atomic functions for lanthanide orbitals and used these in REX calculations to study the electronic structure of the lanthanide halide molecules. Comparisons of calculated orbital energies to observed ionization energies indicate that the REX method gives a good description of the levels which are mostly ligand X(np) in composition. Spin-orbit and crystal-field splittings of the Ln (5p) and (4f) levels are discussed. The question of planar vs. non-planar geometries for the $\operatorname{Ln} X_{3}$ molecules is approached with the aid of $a b$ initio calculations at the SCF level. Although $\mathrm{LaH}_{3}$ and $\mathrm{LaF}_{3}$ are calculated to be non-planar, the inversion barriers for $\mathrm{LaH}_{3}$ and $\mathrm{LaF}_{3}$ (239 and $921 \mathrm{~cm}^{-1}$, respectively) are small, as is the energy required (approximately $380 \mathrm{~cm}^{-1}$ ) to distort planar $\mathrm{LaCl}_{3}$ to the same bond angle as computed for $\operatorname{LaF}_{3}\left(112^{\circ}\right)$. 


\section{Supplementary Material}

A table of parameters for all 15 elements $\mathrm{La}$ through Lu may be obtained from the authors on request.

\section{Acknowledgements}

The authors wish to thank the University of Michigan Computing Center for the use of its facilities and the Academia Sinica of China for fellowship support for Y. Q. Jia.

\section{References}

1 E. W. Kaiser, W. E. Falconer and W. Klemperer, J. Chem. Phys., 56, 5392 (1972).

2 N. I. Popenko, E. Z. Zasorin, V. P. Spiridonov and A. A. Ivanov, Inorg. Chim. Acta, 31, L371 (1978).

3 A. W. Potts and E. P. F. Lee, Chem. Phys. Lett., 82, 526 (1981).

4 E. P. F. Lee, $\Lambda$. W. Potts and J. E. Bloor, Proc. R. Soc. London, Ser. A, 381, 373 (1982).

5 B. Rušcić, G. L. Goodman and J. Berkowitz, J. Chem. Phys., 78, 5443 (1983).

6 G. K. Wertheim, R. L. Cohen, A. Rosencwaig and H. J. Guggenheim, in D. A. Shirley (ed.), 'Electron Spectroscopy', North-Holland, Amsterdam, 1972, p. 813820.

7 C. K. J $\phi$ rgensen and H. Berthou, Chem. Phys. Lett., 13, 186 (1972)

$8 \mathrm{H}$. Berthou, C. K. J $\phi$ rgensen and C. Bonnelle, Chem. Phys. Lett., 38, 199 (1976).

9 C. E. Myers, L. J. Norman, II and L. M. Loew, Inorg. Chem., 17, 1581 (1978).

10 C. F. Bender and E. R. Davidson, J. Inorg. Nucl. Chem., 42, 721 (1980).

11 L.-M. Li, J.-Q. Ren, G..X. Xu, K. H. Hsu and X.-Z. Wang, Int. J. Quantum Chem., 23, 1305 (1983).

12 J. Weber, H. Berthou and C. K. J $\phi$ rgensen, Chem. Phys. Lett., 45, 1 (1977).

13 J. Weber, H. Berthou and C. K. J $\phi$ rgensen, Chem. Phys., $26,69(1977)$
14 P. Pyykkö and L. L. Lohr, Jr., Inorg. Chem., 20, 1950 (1981).

15 L. L. Lohr, Jr. and P. Pyykkö, Chem. Phys. Lett., 62, 333 (1979).

16 L. L. Lohr, Jr. M. Hotokka and P. Pyykkö, Quantum Chem. Prog. Exch., 12, 387 (1980).

17 L. L. Lohr, Jr., M. Hotokka and P. Pyykkö, Int. J. Quantum Chem., 18, 347 (1980).

18 P. Pyykkö and L. Wiesenfeld, Mol. Phys., 43, 557 (1981).

19 L. L. Lohr, Jr., Inorg. Chem., 20, 4229 (1981).

20 P. Pyykkö, J. Organomet. Chem., 232, 21 (1982).

21 A. Viste, M. Hotokka, L. Laaksonen and P. Pyykkö, Chem. Phys., 72, 225 (1982).

22 R. G. Egdell, M. Hotokka, L. Laaksonen, P. Pyykkö and J. G. Snijders, Chem. Phys., 72, 237 (1982).

23 P. Pyykkö and L. Laaksonen, J. Phys. Chem., 88, 4892 (1984).

24 S. Larsson and P. Pyykkö, Chem. Phys., 101, 355 (1986).

25 N. Roosch and P. Pyykkö, Mol. Phys., 57, 193 (1986).

26 J. P. Desclaux, At. Data Nucl. Data Tables, 12, 311 (1973).

27 E. Clementi, D. L. Raimondi and W. P. Reinhardt, J. Chem. Phys., 47, 1300 (1967).

28 N. J. Fitzpatrick and G. H. Murphy, Inorg. Chim. Acta, 111,139 (1986).

29 J. S. Binkley, M. J. Frisch, D. J. DeFrees, K. Raghavachari, R. A. Whiteside, H. B. Schlegel, E. M. Fluder and J. A. Pople, Department of Chemistry, Carnegie-Mellon University, Pittsburgh, Pa., 1983, personal communication.

30 S. Huzinaga (ed.), 'Gaussian Basis Sets for Molecular Calculations', Elsevier, Amsterdam, 1984.

31 R. C. Hariharan and J. A. Pople, Theor. Chim. Acta, 28, 213 (1973).

32 K. P. Huber and G. Herzberg, Molecular Spectra and Molecular Structure. IV. Constants of Diatomic Molecules', Van Nostrand-Reinhold, New York, 1979.

33 A. F. Wells, 'Structural Inorganic Chemistry', Fifth edn., Clarendon, Oxford, 1984.

34 B. Morosin, J. Chem. Phys., 49, 3007 (1968).

35 K. S. Krasnov, N. I. Giricheva and J. Girichev, J.Struct. Chem. (Engl. Transl.), 17, 575 (1976).

36 K. S. Krasnov, (ed.), 'Moleculyarn'ie Postoyann'ic Neorganischeskikh Soedinenii', Khimiya, Leningrad, 1979. 